Please do not remove this page

RMIT

UNIVERSITY

\title{
Investigation of GNSS integrity augmentation synergies with unmanned aircraft sense-and-avoid systems
}

Sabatini, Roberto; Moore, Terry; Hill, Chris; Ramasamy, Subramanian

https://researchrepository.rmit.edu.au/esploro/outputs/9921862884501341/filesAndLinks?institution=61RMIT_INST\&index=null

Sabatini, R., Moore, T., Hill, C., \& Ramasamy, S. (2015). Investigation of GNSS integrity augmentation synergies with unmanned aircraft sense-and-avoid systems. Proceedings of the SAE 2015 AeroTech Congress and Exhibition, 1-11. https://doi.org/10.4271/2015-01-2456

Document Version: Accepted Manuscript

Published Version: https://doi.org/10.4271/2015-01-2456

Repository homepage: https://researchrepository.rmit.edu.au

(C) 2015 SAE International

Downloaded On 2023/04/26 20:08:08 +1000

Please do not remove this page 
Thank you for downloading this document from the RMIT Research Repository.

The RMIT Research Repository is an open access database showcasing the research outputs of RMIT University researchers.

RMIT Research Repository: http://researchbank.rmit.edu.au/

\section{Citation:}

Sabatini, R, Moore, T, Hill, C and Ramasamy, S 2015, 'Investigation of GNSS integrity augmentation synergies with unmanned aircraft sense-and-avoid systems', in Proceedings of the SAE 2015 AeroTech Congress and Exhibition, Warrendale, PA, United States, 22-24 September 2015, pp. 1-11

See this record in the RMIT Research Repository at:

https://researchbank.rmit.edu.au/view/rmit:33428

Version: Accepted Manuscript

Copyright Statement: (C) 2015 SAE International

Link to Published Version:

http://dx.doi.org/10.4271/2015-01-2456 


\title{
Investigation of GNSS Integrity Augmentation Synergies with Unmanned Aircraft Systems Sense-and-Avoid
}

\author{
Roberto Sabatini \\ RMIT University - SAMME, Melbourne, Australia \\ Terry Moore and Chris Hill \\ The University of Nottingham - Nottingham Geospatial Institute (NGI), Nottingham, UK \\ Subramanian Ramasamy \\ RMIT University - SAMME, Melbourne, Australia
}

\begin{abstract}
Global Navigation Satellite Systems (GNSS) can support the development of low-cost and high performance navigation and guidance architectures for Unmanned Aircraft Systems (UAS) and, in conjunction with suitable data link technologies, the provision of Automated Dependent Surveillance (ADS) functionalities for cooperative Sense-and-Avoid (SAA). In non-cooperative SAA, the adoption of GNSS can also provide the key positioning and, in some cases, attitude data (using multiple antennas) required for automated collision avoidance. A key limitation of GNSS for both cooperative (ADS) and non-cooperative applications is represented by the achievable levels of integrity. Therefore, an Avionics Based Integrity Augmentation (ABIA) solution is proposed to support the development of an Integrity-Augmented SAA (IAS) architecture suitable for both cooperative and non-cooperative scenarios. The performances of this IAS architecture were investigated in representative simulation case studies by testing the ability of the SAA system to exploit the predictive (caution) and reactive (warning) integrity flags generated by ABIA. Additionally, the ABIA False Alarm Rate (FAR) and Detection Probability (DP) performances were examined and an initial evaluation of the complementarity with Space-Based and Ground-Based Augmentation Systems (SBAS/GBAS) was accomplished. Simulation results show that the proposed IAS architecture is capable of performing high-integrity conflict detection and resolution when GNSS is used as the primary source of navigation data and there is a clear synergy with state-ofthe art SBAS/GBAS in all applicable flight phases.
\end{abstract}

\section{Introduction}

One of the key challenges encountered by the aviation community for integration of Unmanned Aerial Systems (UAS) into non-segregated airspace is the provision of a certifiable Sense-And-Avoid (SAA) capability. In addition to Space Based Augmentation Systems (SBAS) and Ground Based Augmentation Systems (GBAS), Global Navigation Satellite System (GNSS) augmentation can take the form of additional information being provided and processed by other onboard avionic sensors and systems. In most cases, the additional avionics sensors/systems operate via separate principles than the GNSS and this property can be exploited by suitable data fusion algorithms to generate suitable warnings in case of GNSS data degradation or losses, thereby allowing a timely reaction/correction Page 1 of 10 by the human pilot or by Unmanned Aircraft Vehicle (UAV) Automatic Flight Control Systems (AFCS). A system such as this is called Avionics-Based or Aircraft-Based Augmentation System (ABAS). ABAS, GBAS and SBAS address (using different but synergic approaches) all four cornerstones of GNSS performance augmentation, namely: accuracy, integrity, availability and continuity [1-3]. The ABAS approach is particularly well suited to increase the levels of integrity and accuracy (as well as continuity in multi-sensor data fusion architectures) of GNSS in a variety of mission- and safety-critical applications. In UAS applications, airworthiness requirements for both cooperative and non-cooperative SAA impose stringent GNSS data integrity requirements, which cannot be fulfilled by current SBAS and GBAS technologies in some of the most demanding operational tasks. Therefore, a properly designed Avionics Based Integrity Augmentation (ABIA) system would allow an extended spectrum of autonomous and safety-critical operations including UAS SAA. The ABIA system performs a continuous monitoring of GNSS integrity levels in flight by analysing the relationships between aircraft manoeuvres and GNSS accuracy degradations or signal losses (Doppler shift, multipath, antenna obscuration, signal-to-noise ratio, jamming, etc.). In case of any detected or predicted integrity threshold violation, the ABIA system provides suitable warning or caution signals to the UAV AFCS and to the remote Ground Control Station (GCS), thereby allowing timely correction manoeuvres to be performed. This increased level of integrity could provide a pathway to support unrestricted access of UAS to all classes of airspace. Furthermore, using suitable data link and data processing technologies on the ground, a certified ABAS capability could be a core element of a future GNSS Space-GroundAvionics Augmentation Network (SGAAN) for UAS SAA and other safety-critical aircraft/UA applications.

\section{ABIA System}

Previous research on ABIA systems demonstrated the potential of this technology to enhance GNSS integrity performance in a variety of mission- and safety-critical applications including experimental flight test/flight inspection, precision approach and automatic landing [1-5]. Therefore, an advanced ABIA system was developed for UAS applications (Figure 1). In this system, the on-board sensors provide information on the aircraft relevant flight parameters (navigation data, engine settings, etc.) to an Integrity Flag Generator (IFG), which is also connected to the GNSS system. Using the available 
data on GNSS and the relevant aircraft flight parameters, integrity signals are generated, which are sent to the UAV GCS or used by a Flight Path Optimisation Module (FPOM). This system addresses both predictive and reactive nature of GNSS integrity augmentation by producing suitable integrity flags (cautions and warnings) in case of predicted/ascertained GNSS data losses or unacceptable signal degradations exceeding the Required Navigation Performance (RNP) specified for each phase of flight, and providing guidance information to the remote pilot/autopilot to avoid further data losses/degradations.

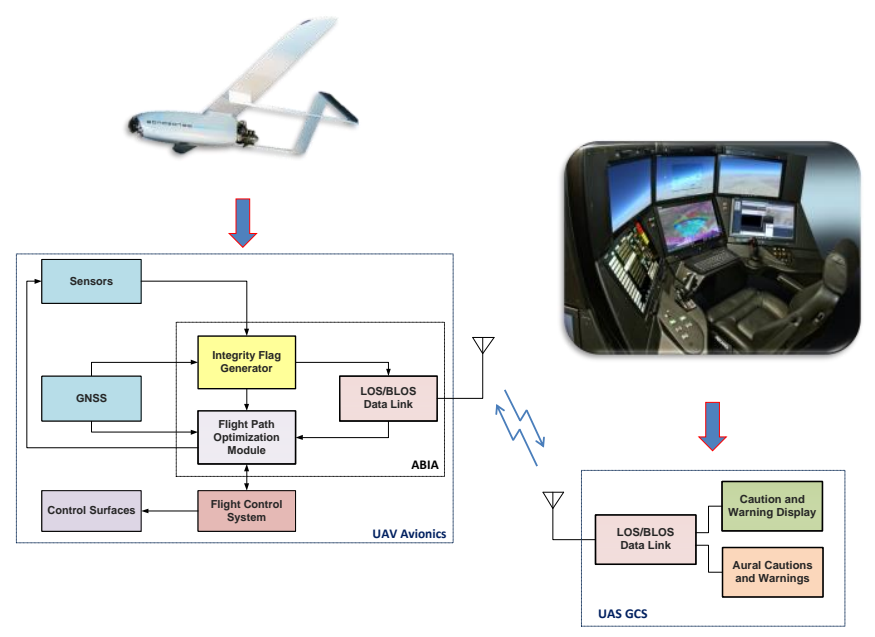

Figure 1. ABIA system architecture for UAS applications.

The IFG module produces the following integrity flags [1-3]:

- Caution Integrity Flag (CIF): a predictive annunciation that the GNSS data delivered to the avionics system is going to exceed the RNP thresholds specified for the current and planned flight operational tasks (GNSS alert status).

- Warning Integrity Flag (WIF): a reactive annunciation that the GNSS data delivered to the avionics system has exceeded the RNP thresholds specified for the current flight operational task (GNSS fault status).

The following definitions of Time-to-Alert (TTA) are applicable to the ABIA system [1-3]:

- ABIA Time-to-Caution (TTC): the minimum time allowed for the caution flag to be provided to the user before the onset of a GNSS fault resulting in an unsafe condition.

- ABIA Time-to-Warning (TTW): the maximum time allowed from the moment a GNSS fault resulting in an unsafe condition is detected to the moment that the ABIA system provides a warning flag to the user.

\section{ABIA Integrity Flag Generator}

The main causes of GNSS data degradation or signal losses in aviation applications were deeply analysed in [1] and are listed below:

- Antenna obscuration (i.e., obstructions from the wings, fuselage or empennage during maneuvers).

- Adverse satellite geometry, resulting in high Position Dilution of

Page 2 of 10
Precision (PDOP)

- Fading, resulting in reduced carrier to noise ratios $\left(\mathrm{C} / \mathrm{N}_{0}\right)$.

- Doppler shift, impacting signal tracking and acquisition/reacquisition time.

- Multipath effects, leading to a reduced $\mathrm{C} / \mathrm{N}_{0}$ and to range/phase errors.

- Interference and jamming.

Understanding the physics of these phenomena and developing reliable mathematical models was essential in order to properly design the ABIA IFG module [1, 6]. Figure 2 illustrates the architecture of the IFG module and its interfaces. The ABIA IFG module is designed to provide CIF and WIF alerts in real-time (i.e., in accordance with the specified TTC and TTW requirements in all relevant flight phases). IFG module inputs are from the GNSS receiver and other aircraft sensors. The GNSS and Sensors Layer (GSL) passes the aircraft Position, Velocity, Time (PVT) and attitude (Euler angles) data (from the on board Inertial Navigation Systems, Air Data Computer, etc.), GNSS data (raw measurements and PVT) and the Flight Control System (FCS) actuators data to the Data Extraction Layer (DEL). At this stage, the required Navigation and Flight Dynamics (NFD) and GNSS Constellation Data (GCD) are extracted, together with the relevant information from an aircraft Three-Dimensional Model (3DM) and from a Terrain and Objects Database (TOD). The 3DM database is a detailed geometric model of the aircraft built in a Computer Aided Three-dimensional Interactive Application (CATIA). The TOD uses a Digital Terrain Elevation Database (DTED) and additional man-made objects data to obtain a detailed map of the surfaces neighbouring the aircraft. In the Integrity Processing Layer (IPL), the Doppler Analysis Module (DAM) calculates the Doppler shift by processing the NFD and GCD inputs.

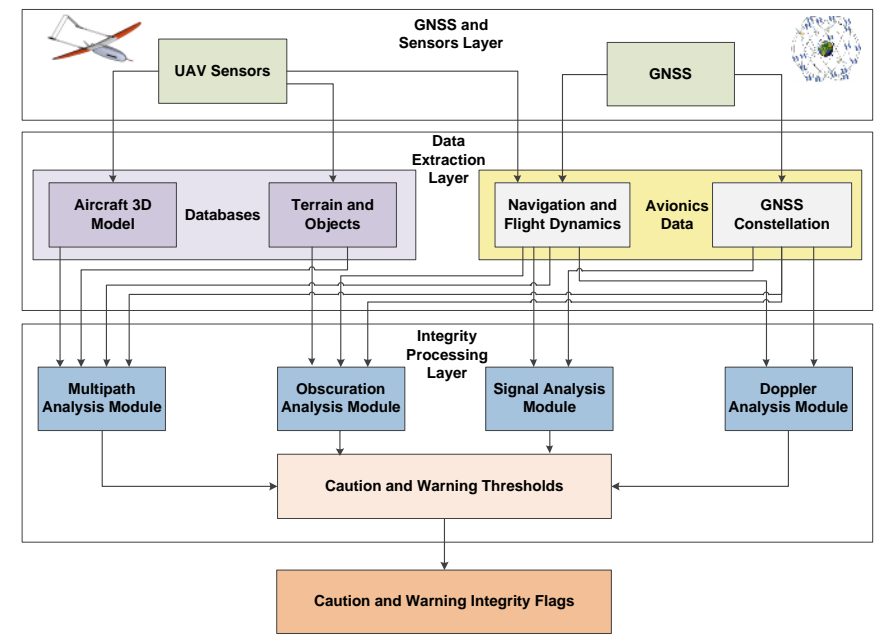

Figure 2. ABIA IFG module architecture.

The Multipath Analysis Module (MAM) processes the 3DM, TOD, GNSS Constellation Module (GCM) and Aircraft Navigation/Dynamics Module (ADM) inputs to determine multipath contributions from the aircraft (wings/fuselage) and from the terrain/objects close to the aircraft. The Obscuration Analysis Module (OAM) receives inputs from ADM, GCS and Aircraft Dynamics SIMulator (ADSIM), and computes the GNSS antenna obscuration matrices corresponding to the various aircraft manoeuvres. The Signal Analysis Module (SAM) calculates the link budget of the direct GNSS signals received by the aircraft in the presence of 
atmospheric propagation disturbances $\left(\mathrm{C} / \mathrm{N}_{0}\right)$, as well as the applicable radio frequency interference and Jamming-to-Signal ratio (J/S) levels. The Integrity Flags Layer (IFL) uses a set of predefined CIF/WIF threshold parameters to trigger the generation of both caution and warning flags associated with antenna obscuration, Doppler shift, multipath, carrier, interference and satellite geometry degradations. The approach adopted to set-up thresholds for the ABIA CIF and WIF integrity flags is depicted in Figure 3. In order to generate CIFs and WIFs that are consistent with current GNSS RNP, the Horizontal and Vertical Accuracy (HA/VA) requirements are introduced in the various flight phases. The 1- $\sigma$ Estimated Position Error (EPE), Estimated Horizontal Error (EHE) and Estimated Vertical Errors (EVE) of a GNSS receiver are calculated using the Position Dilution of Precision (PDOP), Horizontal Dilution of Precision (HDOP) or Vertical Dilution of Precision (VDOP) respectively. The Horizontal Alert Limit (HAL) is defined as the radius of a circle in the horizontal plane, with its centre being at the true position, which describes the region required to contain the indicated horizontal position with a specified probability for a particular navigation mode. Similarly, the Vertical Alert Limit (VAL) is defined as half the length of a segment on the vertical axis, with its centre being at the true position, which describes the region required to contain the indicated vertical position with a specified probability for a particular navigation mode. Multipath integrity flags were defined using the Early-Late Phase (ELP) observable and the range error [7]. A dedicated analysis of the GNSS receiver tracking performance was performed to define the integrity thresholds associated with Doppler and fading effects. When the GNSS measurement errors exceed certain thresholds, the receiver loses lock to the satellites. Since both the code and carrier tracking loops are nonlinear, especially near the threshold regions, only Monte Carlo simulations of the GNSS receiver in different dynamics and SNR conditions can determine the receiver tracking performance. Numerous sources of measurement errors affect the Phase Lock Loop (PLL), Frequency Lock Loop (FLL) and Delay Lock Loop (DLL). PLL, FLL and DLL are used in Scalar Tracking Loops (STL) and Vector Tracking Loops (VTL) are also considered as part of this research. The models described in $[8,9]$ allow determining receiver tracking thresholds in terms of Carrier-to-Noise $\left(\mathrm{C} / \mathrm{N}_{0}\right)$ ratios.

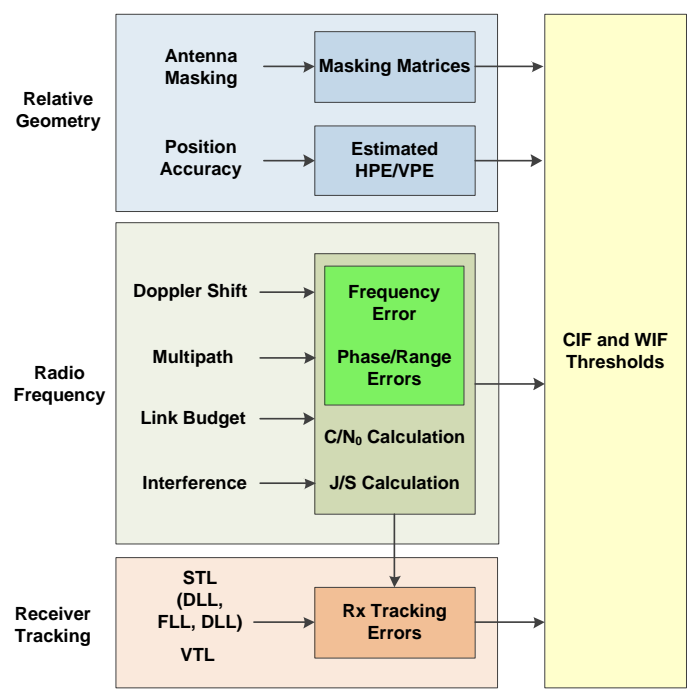

Figure 3. Integrity flag thresholds.

The threshold criterion applicable to the ABIA system is: Page 3 of 10

$$
\left(\frac{\mathrm{C}}{\mathrm{N}_{0}}\right)_{\text {Tresh. }}=\max \left[\left(\frac{\mathrm{C}}{\mathrm{N}_{0}}\right)_{\mathrm{PLL}},\left(\frac{\mathrm{C}}{\mathrm{N}_{0}}\right)_{\mathrm{FLL}},\left(\frac{\mathrm{C}}{\mathrm{N}_{0}}\right)_{\mathrm{DLL}},\left(\frac{\mathrm{C}}{\mathrm{N}_{0}}\right)_{\frac{\mathrm{P}}{\mathrm{FLL}}},\left(\frac{\mathrm{C}}{\mathrm{N}_{0}}\right)_{\mathrm{VTL}}\right]
$$

where $\left(\mathrm{C} / \mathrm{N}_{0}\right)_{\text {PLL }}$ is the minimum $\mathrm{C} / \mathrm{N}_{0}$ for PLL tracking, $\left(\mathrm{C} / \mathrm{N}_{0}\right)_{\mathrm{FLL}}$ is the minimum $\mathrm{C} / \mathrm{N}_{0}$ for FLL tracking, $\left(\mathrm{C} / \mathrm{N}_{0}\right)_{\mathrm{DLL}}$ is the minimum $\mathrm{C} / \mathrm{N}_{0}$ for DLL tracking, $\left(\mathrm{C} / \mathrm{N}_{0}\right)_{\mathrm{PLL}+\mathrm{FLL}}$ is the minimum $\mathrm{C} / \mathrm{N}_{0}$ for combined PLL and FLL tracking and $\left(\mathrm{C} / \mathrm{N}_{0}\right)_{\mathrm{VTL}}$ is the minimum $\mathrm{C} / \mathrm{N}_{0}$ for VTL based tracking. Numerical solution of the tracking equation shows that the weak link in unaided avionics GNSS receivers is the carrier tracking loop threshold due to greater sensitivity to dynamics stress $[8,9]$. Therefore, the $\left(\mathrm{C} / \mathrm{N}_{0}\right)_{\mathrm{PLL}}$ threshold can be adopted in these cases. Using these theoretical and experimental threshold values, we can also calculate the receiver Jamming-to-Signal (J/S) performance for the various cases of practical interest, as described in [9]. When available, flight test data collected in representative portions of the aircraft operational flight envelope (or the results of Monte Carlo simulation) can be used. In avionics receivers, lock detectors are used to assess if the satellite signals are being tracked or not tracked. Code lock detection is very similar to estimating the received $\mathrm{C} / \mathrm{N}_{0}$, inferring that the receiver is operating on or near the correlation peak. The spread spectrum processing gain $\left(G_{p}\right)$ is defined as the ratio of the spread bandwidth to the unspread (baseband) bandwidth and is expressed in $\mathrm{dB}$. The post-correlation Signal-to-Noise $(\mathrm{S} / \mathrm{N})$ ratio is calculated from [10]:

$$
(\mathrm{S} / \mathrm{N})_{\text {post-corr. }}=(\mathrm{S} / \mathrm{N})_{\text {pre-corr. }}+\mathrm{G}_{\mathrm{p}}
$$

The relationship between $\mathrm{C} / \mathrm{N}_{0}$ and jammer signal power $(\mathrm{J})$ is given by [10]:

$$
\frac{\mathrm{C}}{\mathrm{N}}=\left[\mathrm{C} / \mathrm{N}_{0}\right] /\left[1+\frac{\left(\frac{\mathrm{C}}{\mathrm{N}_{0}}\right)\left(\frac{\mathrm{J}}{\mathrm{S}}\right)}{\mathrm{Rc}}\right]
$$

where $\mathrm{N}_{0}$ is the thermal noise power spectral density, Rc is the P-code chipping rate (chips/s), $\mathrm{S}$ is the signal power received at the GNSS antenna input, $\mathrm{C}$ is the carrier power and $\mathrm{J} / \mathrm{S}$ is the jamming-to-signal ratio. The J/S performance of a GNSS receiver at its tracking threshold can be evaluated by the following equation [11]:

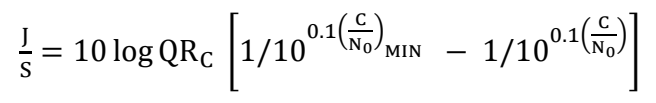

where $\mathrm{Q}$ is the processing gain adjustment factor and is equal to 1 for Narrowband Jammers (NBJ), 1.5 for Spread Spectrum Jammers (SSJ) and 2 for Wideband Gaussian Jammers (WGJ), and $\left(\mathrm{C} / \mathrm{N}_{0}\right)_{\text {MIN }}$ is the receiver tracking threshold $(\mathrm{dB}-\mathrm{Hz})$. When the receiver code is aligned with the transmitted code, the signal power at the band pass output is crushed into approximately $100 \mathrm{~Hz}$ of bandwidth. The processing gain of the GNSS receiver is given as:

$$
\mathrm{G}_{\mathrm{P}}=10 \log \left(\frac{2 \mathrm{C}_{\mathrm{R}}}{\mathrm{T}_{\mathrm{D}}}\right)[\mathrm{dB}]
$$

where $C_{R}$ is the chipping rate and $T_{D}$ is the data period. For the C/Acode this works out to be about $43 \mathrm{~dB}$. Typical avionics receivers have a cut off value at $10 \mathrm{~dB}$, which means that if the value is less than this, the satellite signal level is too low to be used in the positioning computations. Therefore, an additional threshold criterion to be accounted for in the ABIA system is given as:

$$
S / N_{\text {post-corr. }}=S / N_{\text {pre-corr. }}+G_{p} \geq 10 \mathrm{~dB}
$$

During experimental flight test activities performed with unaided L1 C/A code avionics receivers, it was also found that, in a variety of dynamics conditions, a $\mathrm{C} / \mathrm{N}_{0}$ of $25 \mathrm{~dB}-\mathrm{Hz}$ was sufficient to keep tracking of the satellites [11]. Consequently, taking a $2 \mathrm{~dB}$ margin for the CIF, the following additional criteria are adopted for S/N integrity 
flags. The criteria for caution and warning integrity flag generation are listed in Tables 1 and 2 respectively.

Table. 1. CIF criteria.

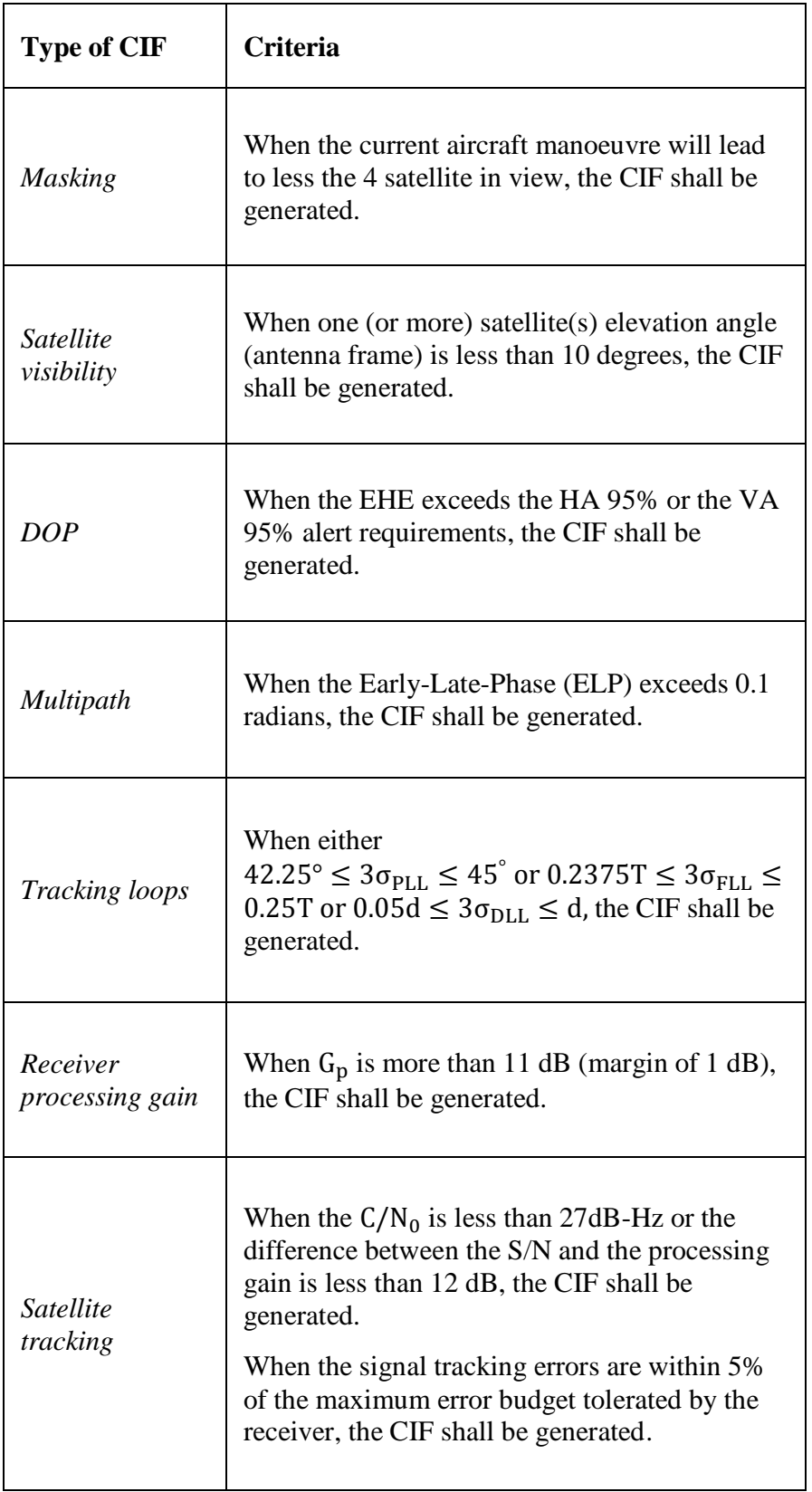

\section{SBAS/GBAS Integrity Flag Generation}

During the landing phase, a GNSS Landing System (GLS) has to be augmented by GBAS in order to achieve the RNP, as well as Horizontal and Vertical Protection Level (HPL and VPL) requirements. In the case of Local Area Augmentation System (LAAS), the system allows the adoption of multiple Differential Global Positioning System (DGPS) reference receivers. In order to perform a comparative evaluation of the ABIA IFG module with GBAS and SBAS, the GBAS/SBAS Integrity Flag Generation Processes (IFGPs) are considered as illustrated in Figures 4 and 5 respectively. Vertical and Lateral Protection Level (VPL and LPL) for SBAS and GBAS are calculated in line with the Minimum Page 4 of 10
Operational Performance Standards (MOPS) for WAAS and LAAS $[12,13]$.

Table. 2. WIF criteria

\begin{tabular}{|c|c|}
\hline Type of WIF & Criteria \\
\hline Masking & $\begin{array}{l}\text { When less than } 4 \text { satellites are in view, the WIF } \\
\text { shall be generated. }\end{array}$ \\
\hline $\begin{array}{l}\text { Satellite } \\
\text { visibility }\end{array}$ & $\begin{array}{l}\text { When one (or more) satellite(s) elevation angle } \\
\text { is less than } 5 \text { degrees, the WIF shall be } \\
\text { generated. }\end{array}$ \\
\hline$D O P$ & $\begin{array}{l}\text { When the EHE exceeds the HAL or the EVE } \\
\text { exceeds the VAL, the WIF shall be generated. }\end{array}$ \\
\hline Multipath & $\begin{array}{l}\text { When the multipath range error exceeds } 1 \\
\text { meter, the WIF shall be generated. } \\
\text { When the multipath ranging error exceeds } 2 \\
\text { metres and the aircraft flies in proximity of the } \\
\text { ground (below } 500 \mathrm{ft} \text { AGL), the WIF shall be } \\
\text { generated. }\end{array}$ \\
\hline Tracking loops & $\begin{array}{l}\text { When either } 3 \sigma_{\mathrm{PLL}}>45^{\circ} \text { or } 3 \sigma_{\mathrm{FLL}}>1 / 4 \mathrm{~T} \text { or } \\
3 \sigma_{\mathrm{DLL}}>\mathrm{d} \text {, the WIF shall be generated. }\end{array}$ \\
\hline $\begin{array}{l}\text { Receiver } \\
\text { processing gain }\end{array}$ & $\begin{array}{l}\text { When } G_{p} \text { is less than } 9 \mathrm{~dB} \text { (margin of } 1 \mathrm{~dB} \text { ), the } \\
\text { WIF shall be generated. }\end{array}$ \\
\hline $\begin{array}{l}\text { Satellite } \\
\text { tracking }\end{array}$ & $\begin{array}{l}\text { When the signal tracking loss conditions occur, } \\
\text { the WIF shall be generated. } \\
\text { When the } \mathrm{C} / \mathrm{N}_{0} \text { is less than } 25 \mathrm{~dB}-\mathrm{Hz} \text { or the } \\
\text { difference between the } \mathrm{S} / \mathrm{N} \text { and the processing } \\
\text { gain is less than } 10 \mathrm{~dB} \text {, the WIF shall be } \\
\text { generated. }\end{array}$ \\
\hline
\end{tabular}

Additionally, [13] provides the so-called Continuity of Protection Levels in terms of Predicted Lateral and Vertical Protection Levels (PLPL and PVPL). According to the LAAS MOPS, avionics-based functionalities such as ABAS/ABIA would support PLPL/PVPL calculations to generate appropriate caution flags. In our research, we propose that a similar functionality be implemented in SBAS and supported by the ABIA system measurements. As both GBAS and SBAS use redundant GNSS satellite observations to generate integrity flags (i.e., 5 satellites for LAAS and 6 satellites for WAAS), the number of satellites in view can be used to set additional thresholds. In order to perform a comparative evaluation of the ABIA IFG module 
with GBAS and SBAS, the GBAS/SBAS Integrity Flag Generation Processes (IFGPs) are illustrated in Figures 4 and 5 respectively.

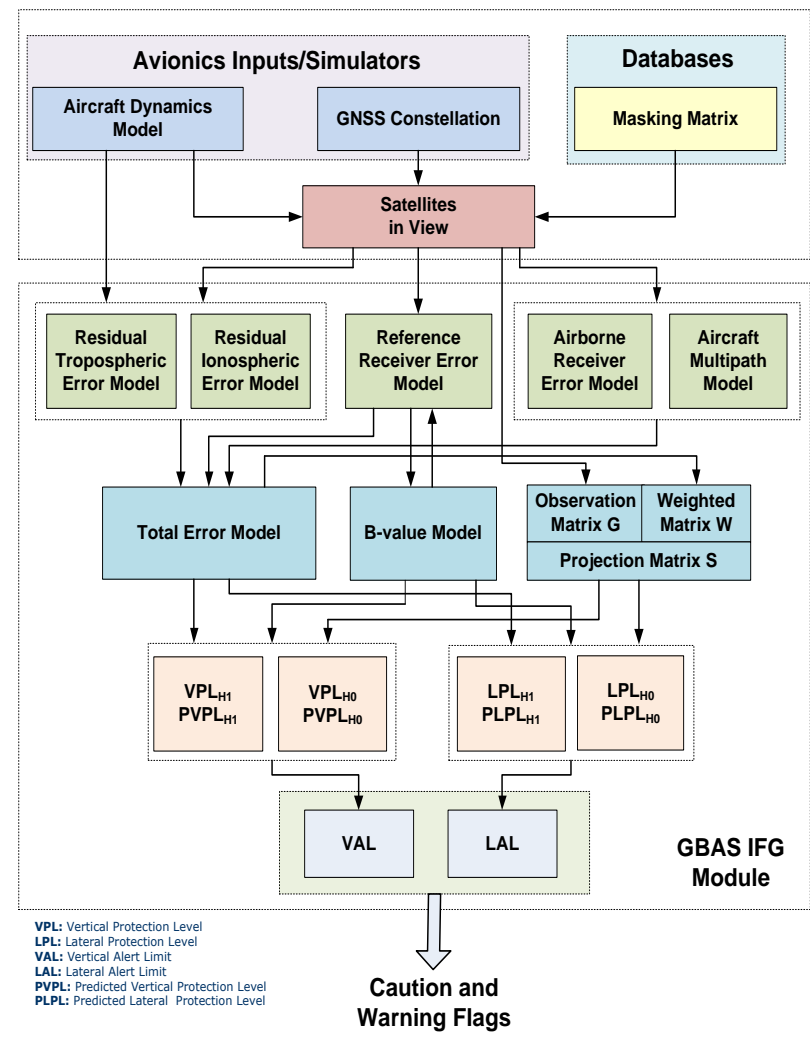

Figure 4. GBAS IFG.

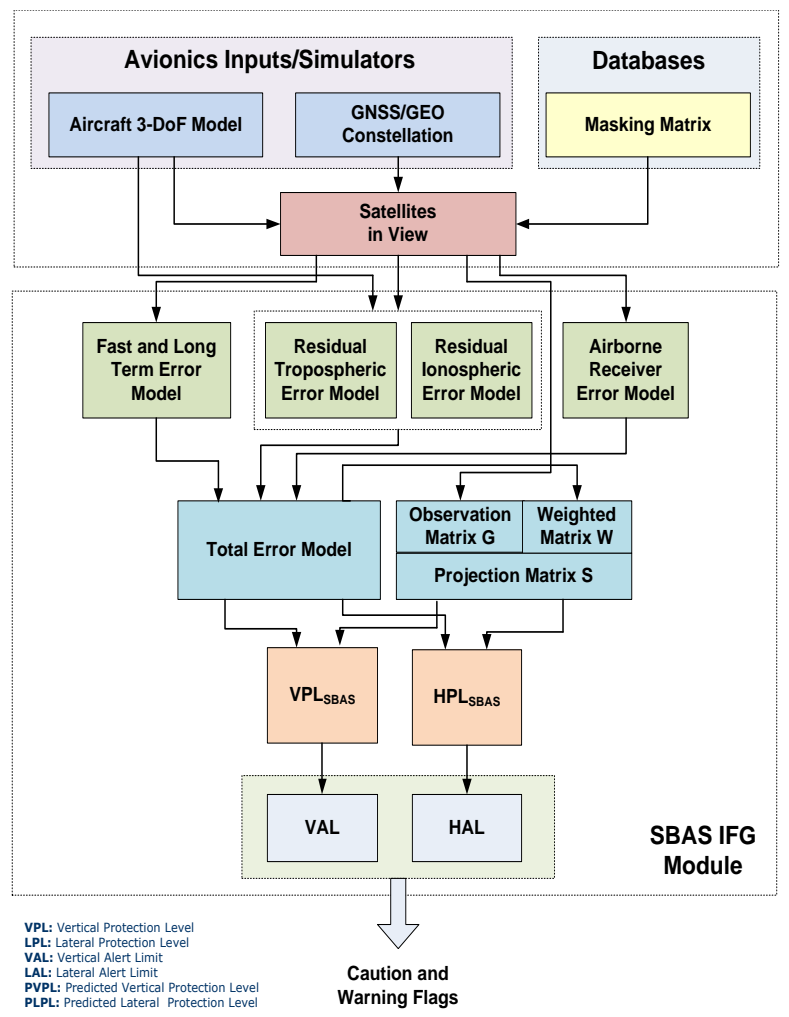

Figure 5. SBAS IFG.

Page 5 of 10
The SBAS/GBAS CIF and WIF criteria are tabulated in Tables 3 and 4 respectively.

Table. 3. SBAS/GBAS CIF criteria.

\begin{tabular}{|l|l|}
\hline \multirow{2}{*}{$\begin{array}{l}\text { Type of CIF } \\
\begin{array}{l}\text { Continuity of } \\
\text { protection } \\
\text { levels }\end{array}\end{array}$} & $\begin{array}{l}\text { Criteria } \\
\text { exceeds LAL, the CIF shall be generated. }\end{array}$ \\
\cline { 2 - 2 } & $\begin{array}{l}\text { When PVPL } \\
\text { exceeds LAL, the CIF shall be generated. }\end{array}$ \\
\hline \multirow{3}{*}{$\begin{array}{l}\text { Satellite } \\
\text { visibility }\end{array}$} & $\begin{array}{l}\text { When number of satellites in view is less than 5, } \\
\text { the GBAS CIF shall be generated. }\end{array}$ \\
\cline { 2 - 2 } & $\begin{array}{l}\text { When number of satellites in view is less than 7, } \\
\text { the SBAS CIF shall be generated. }\end{array}$ \\
\hline
\end{tabular}

Table. 4.SGBAS/GBAS WIF criteria.

\begin{tabular}{|l|l|}
\hline \multirow{2}{*}{$\begin{array}{l}\text { Type of WIF } \\
\begin{array}{l}\text { Continuity of } \\
\text { protection } \\
\text { levels }\end{array}\end{array}$} & $\begin{array}{l}\text { Criteria } \\
\text { exceeds HAL, the WIF shall be generated. }\end{array}$ \\
\cline { 2 - 2 } & $\begin{array}{l}\text { When VPL } \\
\text { HAL, the WIF shall be generated. }\end{array}$ \\
\hline \multirow{3}{*}{$\begin{array}{l}\text { Satellite } \\
\text { visibility }\end{array}$} & $\begin{array}{l}\text { When number of satellites in view is less than 4, } \\
\text { the GBAS WIF shall be generated. }\end{array}$ \\
\cline { 2 - 2 } & $\begin{array}{l}\text { When number of satellites in view is less than 6, } \\
\text { the SBAS WIF shall be generated. }\end{array}$ \\
\hline
\end{tabular}

\section{Sense-and-avoid System}

Cooperative and non-cooperative SAA are implemented to address UAS safe integration into the non-segregated airspace. The SAA capability can be defined as the automatic detection of possible conflicts (i.e., collision threats) by the UAV platform and the implementation of avoidance manoeuvres to prevent the identified collision threats. As part of our research, the possible synergies attainable with the adoption of different detection, tracking and trajectory generation algorithms were studied. Additionally, the error propagation from different sources and the impacts of host and intruders dynamics on the ultimate SAA solution were investigated. The system detection range and FOR have to be adequate to ensure separation from the intruder to prevent a probable near mid-air collision. This criterion is also naturally applicable in the case of small UAV since the vast majority of mid-air collision events occur below $3000 \mathrm{ft}$ [14]. A number of cooperative and non-cooperative sensors/systems have been studied recently. Cooperative systems typically include Traffic Collision Avoidance System (TCAS) / Airborne Collision Avoidance System (ACAS) and Automatic Dependent Surveillance Broadcast (ADS-B). Optical, thermal, LIDAR, Millimeter Wave (MMW) radar and acoustic sensors are adopted as part of non-cooperative sensors. 


\section{Uncertainty Volume}

Error analysis is performed to determine the overall uncertainty volume in the airspace surrounding the intruder tracks. This is accomplished by considering both the navigation and the tracking errors affecting the measurements and translating them to unified range and bearing uncertainty descriptors. The shape of the combined navigation and tracking uncertainty volume is conveniently described using spherical harmonics. Using a spherical coordinates frame with origin at the host UA centre of mass, the range and bearing errors associated with the intruder tracking process is transformed into a local coordinate frame (either host or intruder body frame). Both navigation and tracking error ellipsoids are generated and the overall uncertainty volume is obtained by combining the two error ellipsoids $[15,16]$. When the errors are not correlated, vector analysis is performed and when the errors are correlated, tensors analysis is adopted to obtain covariant and contravariant components.

\section{ABIA/SAA Systems Integration}

The Position, Velocity and Attitude (PVA) measurements are typically obtained by adopting multi-sensor data fusion techniques [17-19]. An initial flight path is generated using the ADM. The IFG module run is performed on that nominal trajectory. Based on a Boolean decision logic that sorts sensors data based on estimated performance parameters, the C-SAA or non-cooperative SAA sensors are used for safe separation. If both the safe separation thresholds are violated and a mid-air collision threat is detected the WIF is generated. To prevent any WIF, the flight path optimization process starts when the first CIF is generated. Pseudo-Spectral Optimisation (PSO) and Differential Geometry Optimization (DGO) techniques are used to generate a new optimised trajectory free of any integrity degradations. Depending on the relationship between the available time-to-collision and the computation time according to PSO and DGO trajectory solutions, the optimised trajectory data are sent to the AFCS (and/or to the ground pilot) for execution of the avoidance manoeuvres. In the trajectory optimisation process, time is used as the cost functional and the aircraft dynamics model/satellite elevations are used as path constraints. The ABIA/SAA integrated architecture is illustrated in Figure 6. The implemented decision logic is based on minimisation of the following cost function [20]:

$$
\begin{gathered}
J=w_{t} \cdot t_{S A F E}+w_{f} \int[S F C \cdot T(t)] d t-w_{d} \cdot D_{\min } \\
-w_{i d} \cdot \int D(t) d t
\end{gathered}
$$

where $\mathrm{D}(\mathrm{t})$ is the estimated distance of the generated avoidance trajectory points from the avoidance volume associated with the obstacle, $D_{\min }=\min [D(t)]$ is the estimated minimum distance of the avoidance trajectory from the avoidance volume, $\mathrm{t}_{\mathrm{SAFE}}=\left.\mathrm{t}\right|_{\mathrm{D}_{\min }}$ is the time at which the safe avoidance condition is successfully attained, SFC $\left[\frac{\mathrm{kg}}{\mathrm{N}} \cdot \mathrm{s}\right]$ is the specific fuel consumption, $\mathrm{T}(\mathrm{t})$ is the thrust profile. $\mathrm{w}_{\mathrm{t}}, \mathrm{w}_{\mathrm{f}}, \mathrm{w}_{\mathrm{d}}, \mathrm{w}_{\mathrm{id}}$ are the weightings attributed to time, fuel, distance and integral distance respectively. In time-critical avoidance applications (i.e., closing-up obstacles with high relative velocities) appropriate higher weightings are used for the time and distance cost elements.

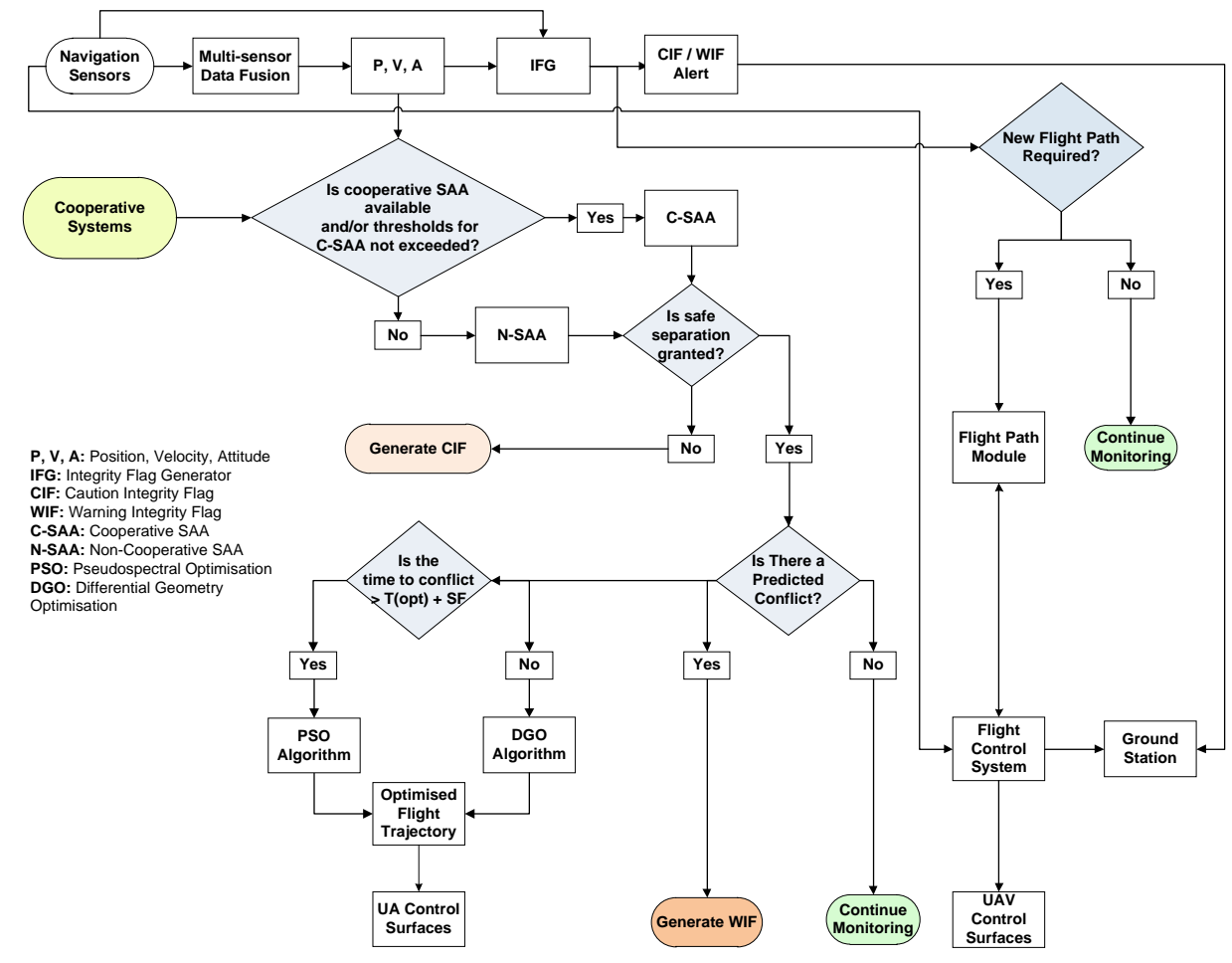

Figure 6. ABIA/SAA integrated architecture.

\section{Simulation Results}

A number of simulation case studies were performed to evaluate the performance of the ABIA/SAA integrated architecture. A GNSS constellation simulator was implemented to support GNSS satellite visibility, signal and geometry analysis. Using CATIA-P3, a detailed $\mathrm{ADM}$ was developed and an ADSIM was implemented to generate the nominal flight path trajectory and Euler angles. TOD was used to run the MPS and using a DTED, it a detailed map of the terrain beneath the aircraft was obtained. Providing the aircraft trajectory inputs from

Page 6 of 10 
the ADSIM module, terrain elevation data were automatically extracted and fed to the TOM module where they are integrated with the database of man-made objects (e.g., buildings).

\section{Aircraft 3-D Model}

Various geometric parameters were extracted from the literature to draw a detailed CATIA model of the AEROSONDE UAV as illustrated in Figure 7 [17]. To calculate the Antenna Masking Matrix (AMM) and the corresponding satellite visibility conditions, the antenna location were included in the model. After creating the 3-D aircraft surface model, the corresponding CAD file was transformed in a Stereolithography (STL) file format. An STL file is a convenient representation of a complex 3D surface geometry, made by a number of oriented triangles (mesh). Each of these triangles is described by two elements: the first is a unit normal vector to the facet; the second element is a set of three points listed in counter clockwise order representing the vertices of the triangle. This representation is ideally suited for the ABIA simulation environment as shown in Figure 8. Using this representation, the AMMs in pitch and roll are generated calculating all possible intersections of the aircraft body (all triangular surfaces) with the LOS antenna-satellites. In order to generate CIF/WIF associated to critical UAV antenna masking conditions, a dedicated analysis is required taking into account the simultaneous variation of pitch and bank. In general, a satellite is geometrically visible to the GNSS receiver only if its elevation in the antenna frame is above the Earth horizon and the antenna elevation mask. It should be noted that even high performance avionics GNSS antennas have a gain patterns that is typically below $-3 \mathrm{~dB}$ at about 5 degrees elevation and, as a consequence, their performance become marginal below this limit. In order to determine if a satellite is obscured, the LOS of the satellite with respect to the antenna phase centre has to be determined.

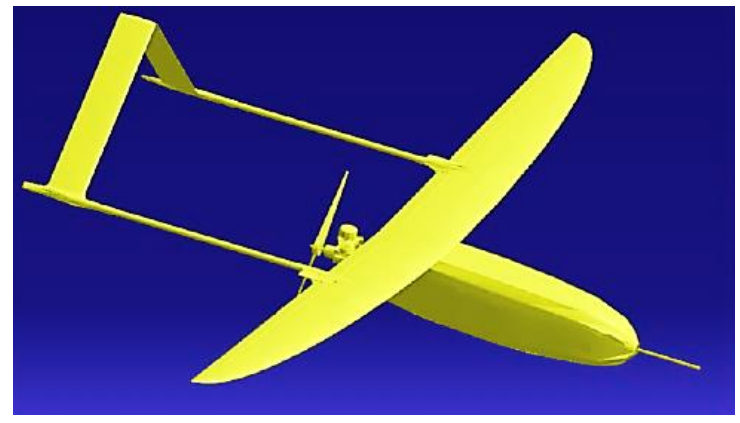

Figure 7. AEROSONDE 3-D CATIA model.

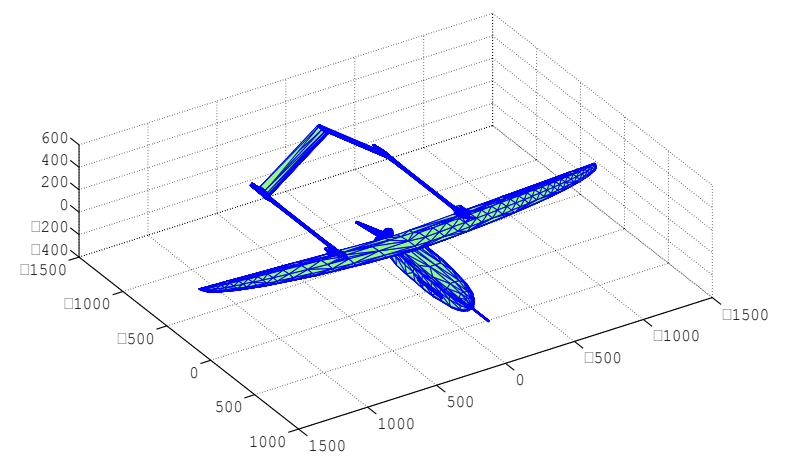

Figure 8. AEROSONDE STL file imported in MATLAB.
The location of the AEROSONDE GPS antenna extracted from the literature is shown in Figure 9.

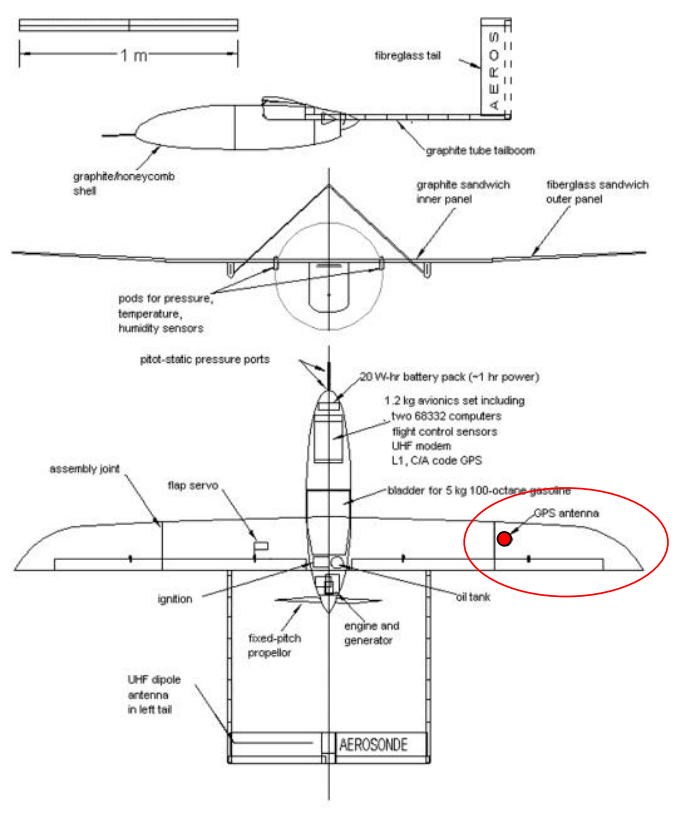

Figure 9. AEROSONDE antennae locations. Adapted from [17].

\section{IFG Simulation}

In order to validate the design of the ABIA IFG module, a MATLAB ${ }^{\circledR}$ simulation activity was performed employing the algorithms developed during this research. The simulated AEROSONDE UAV trajectory included the following flight phases:

- $\quad$ Climb phase (0-300s);

- $\quad$ Turning climb phase (300-600s);

- $\quad$ Straight and level (cruise) phase (600-900s);

- Level turn phase (900-1200s)

- Turn and descend phase (1200-1500s);

- Descend (straight approach) phase (1500-1800s);

The combined GPS/GALILEO constellation was simulated and the GNSS receiver tracking loops were modelled with a flat random vibration power curve from $20 \mathrm{~Hz}$ to $2000 \mathrm{~Hz}$ with amplitude of $0.005 \mathrm{~g}^{2} / \mathrm{Hz}$ and the oscillator vibration sensitivity $\mathrm{S}_{\mathrm{v}}\left(\mathrm{f}_{\mathrm{m}}\right)=1 \times$ $10^{-9}$ parts $/ g$. All CIFs and WIFs relative to antenna masking, geometric accuracy degradations, SNR, multipath and Doppler shift were generated. The main results obtained with the simulated GPS constellation are shown in Table 5. In some cases, the CIF was generated but it was not followed by the WIF (this was due to a temporary adverse relative geometry not leading to GNSS signal losses). During the level turn and turning descent phases, the CIF was followed by the WIF.

It was also observed that the CIF was always triggered at least 2 seconds before the successive WIF onset (up to 13 seconds in one case during the turning descent phase). These results are consistent with previous ABIA research on manned aircraft applications [1-3] and corroborate the validity of the models developed for the CIF/WIF thresholds. It was also observed that the CIF was always triggered at 
least 2 seconds before the successive WIF onset. This evidence is particularly important for the ABIA system design.

Table. 5. IFG simulation results.

\begin{tabular}{|c|c|c|}
\hline $\begin{array}{l}\text { Flight } \\
\text { Phase }\end{array}$ & CIF & WIF \\
\hline Climb & --- & --- \\
\hline $\begin{array}{l}\text { Turning } \\
\text { Climb }\end{array}$ & $\begin{array}{l}334 \sim 374 \mathrm{~s}, \\
426 \sim 446 \mathrm{~s} \\
517 \sim 558 \mathrm{~s}\end{array}$ & --- \\
\hline Cruise & $874 \sim 900$ s & --- \\
\hline $\begin{array}{l}\text { Level } \\
\text { Turn }\end{array}$ & $901 \sim 1200 \mathrm{~s}$ & $\begin{array}{c}903 \sim 906 \mathrm{~s}, 913 \mathrm{~s}, 920 \sim 924 \mathrm{~s}, 930 \sim 931 \mathrm{~s} \text {, } \\
938 \sim 942 \mathrm{~s}, 948 \sim 949 \mathrm{~s}, 956 \sim 959 \mathrm{~s}, \\
966 \sim 967 \mathrm{~s}, 974 \sim 977 \mathrm{~s}, 984 \sim 985 \mathrm{~s}, \\
992 \sim 995 \mathrm{~s}, 1002 \sim 1003 \mathrm{~s}, 1110 \sim 1113 \mathrm{~s}, \\
1020 \sim 1021 \mathrm{~s}, 1028 \sim 1031 \mathrm{~s}, 1128 \sim 1129 \mathrm{~s}, \\
1136 \sim 1139 \mathrm{~s}, 1146 \sim 1147 \mathrm{~s}, 1154 \sim 1157 \mathrm{~s} \text {, } \\
1164 \sim 1165 \mathrm{~s}, 1172 \sim 1175 \mathrm{~s}, 1182 \sim 1183 \mathrm{~s}, \\
1190 \sim 1192 \mathrm{~s}, 1200 \mathrm{~s}\end{array}$ \\
\hline $\begin{array}{l}\text { Turning } \\
\text { Descent }\end{array}$ & $\begin{array}{l}1201 \sim 1441 \mathrm{~s}, \\
1448 \sim 1464 \mathrm{~s}, \\
1471 \sim 1487 \mathrm{~s} \\
1494 \sim 1500 \mathrm{~s}\end{array}$ & $\begin{array}{c}1204 \mathrm{~s}, 1223 \sim 1224 \mathrm{~s}, 1247 \sim 1249 \mathrm{~s}, \\
1272 \sim 1273 \mathrm{~s}, 1296 \sim 1297 \mathrm{~s}, 1320 \sim 1321 \mathrm{~s}, \\
1344 \sim 1367 \mathrm{~s}, 1368 \mathrm{~s}, 1391 \sim 1392 \mathrm{~s}, \\
1414 \sim 1415 \mathrm{~s}, 1438 \sim 1439 \mathrm{~s}, 1461 \sim 1462 \mathrm{~s}, \\
1484 \sim 1485 \mathrm{~s}\end{array}$ \\
\hline Descent & $1503 \sim 1800 \mathrm{~s}$ & $1504 \sim 1508 \mathrm{~s}$ \\
\hline
\end{tabular}

In fact, it is evident that the availability of a usable CIF represents a significant progress in this research with the potential for both manned aircraft and UAVs to recover from mission- and safety-critical flight conditions potentially leading to GNSS data losses. Therefore, it is envisaged that a properly designed ABIA FPM could take full advantage of this predictive behaviour, allowing the UAV to correct its flight trajectory/attitude in order to avoid the occurrence of the critical GNSS data losses. Additionally, it is possible that this predictive behaviour be exploited in the pursuit of a GNSS based autolanding capability. Assuming that all WIFs are true GNSS outages, we have a number of True Caution Flags (TCF), corresponding to the CIFs followed by WIFs. There are also some CIFs not followed by WIFs that we identify as False Caution Flags (FCF). Therefore, the Caution Detection Rate (CDR) can be calculated as:

$$
\mathrm{CDR}=\frac{\mathrm{TCF}}{\mathrm{TCF}+\mathrm{FCF}}
$$

and the False Caution Rate (FCR) is:

$$
\mathrm{FCR}=1-\mathrm{CDR}
$$

Since SBAS and GBAS are integrated in the IFG, the analysis is performed by flight phase and then a cumulative measure is also obtained. With these assumptions, considering all flight phases, the total CDR is $60 \%$ and the FCR is $40 \%$. However, if we consider only the final flight phases (were GBAS/ABIA synergies are maximised), the CDP is actually $100 \%$ and the ABIA CIFs bring an improvement of $12 \%$ with respect to a purely reactive integrity approach (e.g., RAIM).

\section{Page 8 of 10}

\section{ABIA/SAA Simulation}

The ABIA integration into an existing UAV SAA architecture was studied in cooperative and non-cooperative SAA scenarios. The test platforms used were 3DoF ADM:

- AEROSONDE UAV (ABIA host platform) and

- AIRBUS 320 (A320) and AEROSONDE UAV intruders.

In all the scenarios, an avoidance volume (sum of navigation and tracking errors) was generated by the SAA system [15]. PSO or constrained DGO techniques were used to generate the new trajectory based on the available time to conflict (host entering the avoidance volume). The avoidance trajectory was initiated by the SAA system when the probability of collision exceeded the required threshold value. Time and fuel were used in the cost functional, the dynamic model as dynamic constraint, and the elevation criteria as path constraints for both PSO and DGO techniques. Boundary conditions were set from the value of the flight parameters at CIF time step. A collision avoidance trajectory free of GNSS integrity degradation was generated. Figure 8 illustrates the cooperative SAA test scenario wherein two AEROSONDE UAV (1 ABIA host platform and 1 intruder) are $90^{\circ}$ off track at the same Flight Level (FL). The collision is detected and resolved and as a result the host and intruder UAVs avoid colliding in mid-air. The host UAV platform equipped with ABIA/SAA is able to generate an avoidance trajectory without any CIF/WIF occurrences. Three different points are shown on the ABIA/SAA host platform trajectory in Figure 10:

- SAA Break-off Point: Corresponding to the point where the host UA initiates the avoidance trajectory (commanded by the SAA system). The cost function criteria adopted in this case is minimum time.

- SAA Safe Manoeuvring Point: Corresponding to the point where the host UAV can manoeuvre safely (any manoeuvre within its operational flight envelope) has 0 ROC. From this point onwards the SAA cost function criteria switches to minimum time and minimum fuel to get back on the original (desired) track.

- ABIA Re-join Point: Corresponding to the point where the host UAV re-joins the original (desired) track without GNSS data degradations.

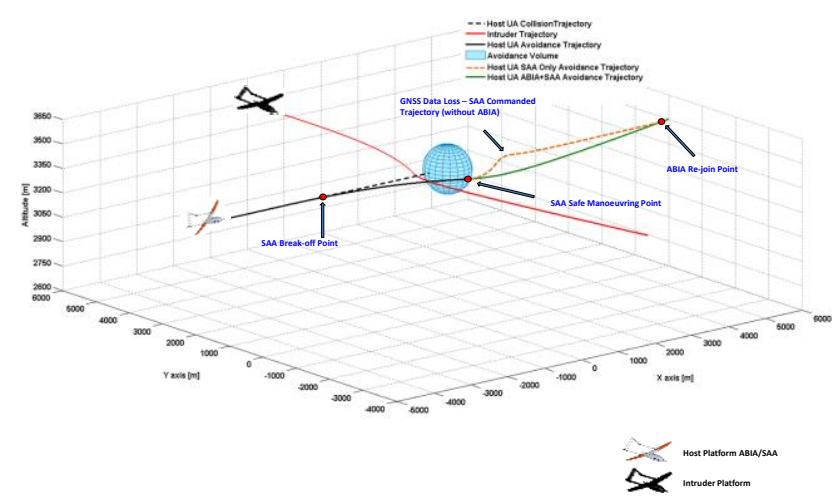

Figure 10. Illustration of reference points. 
Figure 11 illustrates the non-cooperative SAA test scenario wherein AEROSONDE (ABIA host platform) UAV and an A320 are on the same FL but are $90^{\circ}$ off track to each other. The horizontal and vertical separation obtained is illustrated in Figure 12.

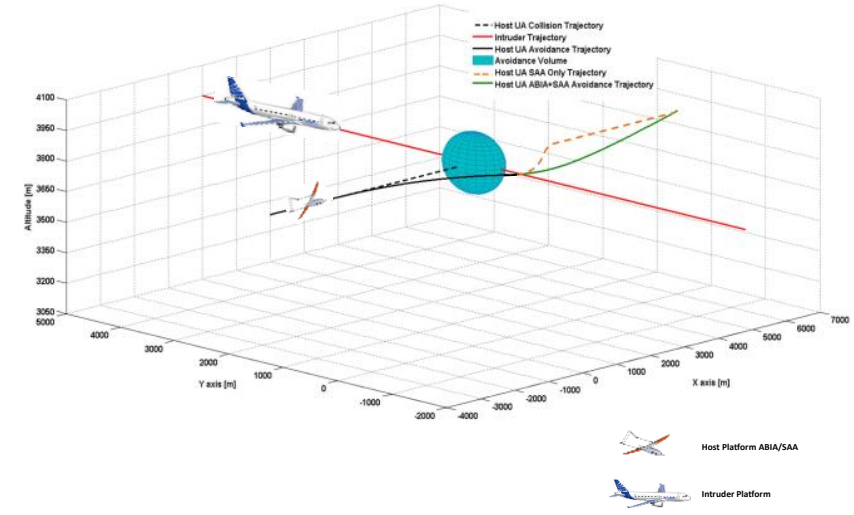

Figure 11. UAV $90^{\circ}$ collision non-cooperative SAA scenario.
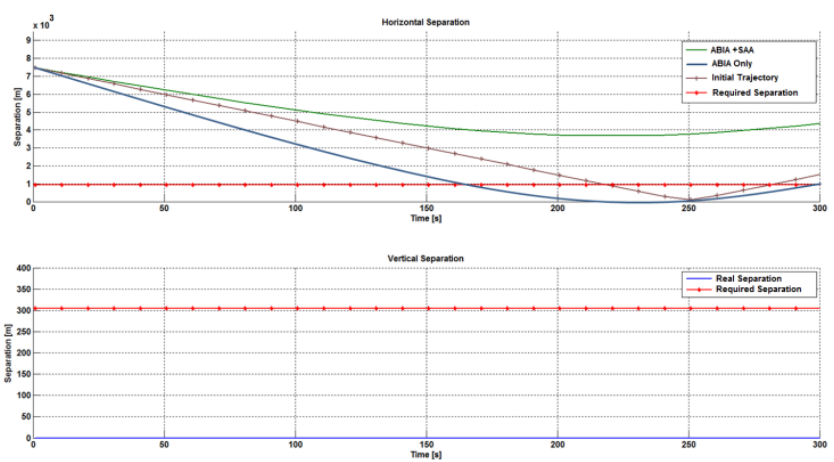

Figure 12. Obtained horizontal and vertical separation.

Figure 13 illustrates the cooperative SAA test scenario wherein AEROSONDE (ABIA host platform) UAV and two intruders (AEROSONDE UAVs) are on the same FL. One intruder UAV is $90^{\circ}$ off track and the other is on a head-on collision with the host UAV.

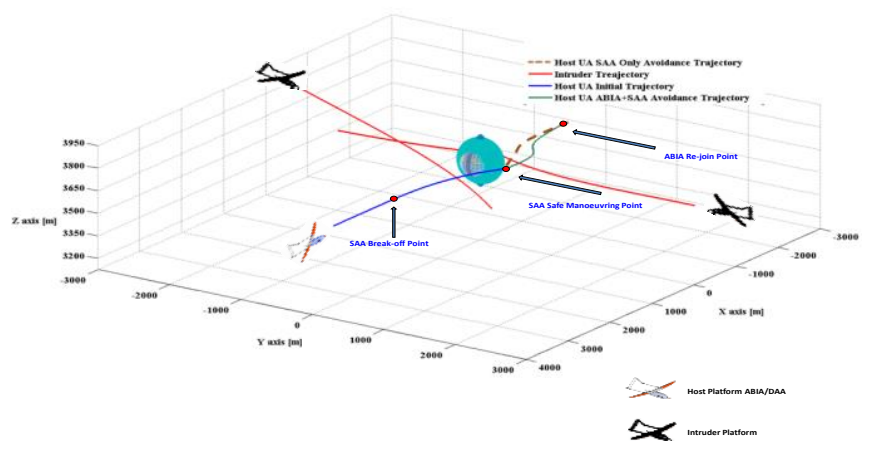

Figure 13. 3 UAV collision cooperative SAA scenario.

Page 9 of 10
The simulation results demonstrate that the ABIA IFG module is capable of generating integrity flags to provide both caution and warning signals when GNSS signals are degraded or lost. After the integrity caution flag is generated, the time available for the pilot/autopilot to react (before the integrity event is detected and the warning flag is generated), is at least 2 seconds. This TTC can support safety-critical tasks including GLS curved/segmented precision approach and automatic landing applications. Data analysis showed that the ABIA system can provide useful integrity signals for CAT-III precision approach and automatic landing (automated and real-time FPO is essential in this case). In the C-SAA and N-SAA scenarios investigated and in the dynamic conditions explored, all near mid-air collision threats were successfully avoided by implementing adequate trajectory optimisation algorithms. Both PSO and DGO algorithms proved successful in C-SAA and N-SAA scenarios depending on the available time for the optimisation loops (distance host-intruders and relative dynamics). Based on the position uncertainty of the host aircraft an optimised avoidance trajectory without any GNSS data losses is constructed around the resulting avoidance volume. In case of jamming, the overall avoidance volume is obtained by combining the tracking error of the jamming signal radiation pattern (main lobe in the case of a directional jammer) and the navigation error of the host platform. The optimised avoidance trajectory is constructed tangential to the radiation pattern of the jammer by taking into account the position uncertainty of the host platform. For the directional jamming scenario shown in Figure 14, a preferential right turn was imposed to avoid the UAV entering the Forward Line of Own Troops (FLOT) of red (i.e., enemy) forces. In this case, the optimal jamming avoidance trajectory was generated with weights set to $\mathrm{w}_{\mathrm{t}}=100 \%, \mathrm{w}_{\mathrm{f}}=0 \%$, $\mathrm{w}_{\mathrm{d}}=0 \%, \mathrm{w}_{\mathrm{id}}=0 \%$ (i.e., fuel and distance objectives set to zero in the cost function) and using the ABIA criteria to avoid degradation or losses of GNSS data during the jammer avoidance manoeuvre. In this simulation, the constraints imposed by ABIA in terms of UAV platform dynamics and GNSS satellite elevation angles were considered to generate the optimised avoidance trajectories, thus preventing degradation or losses of navigation data during the whole jammer avoidance manoeuvre.

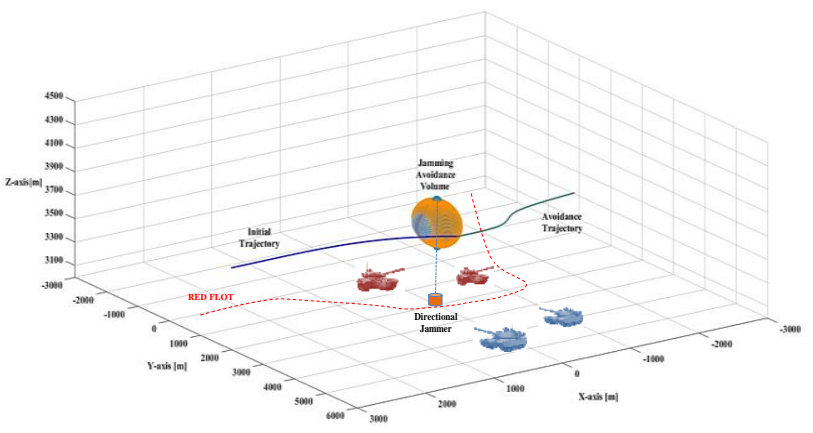

Figure 14. Trajectory in the presence of directional jammer.

These results confirm that ABIA contributes to providing an IntegrityAugmented SAA (IAS) solution that is well suited for an extension of the current GBAS/SBAS augmentation network in a variety of mission- and safety-critical applications including UAS SAA. The inclusion of ABIA thus provides solid foundations for the development of a future SGAAN architecture meeting the requirements for manned and unmanned aircraft separation maintenance and collision avoidance tasks for all flight phases. 


\section{Conclusions and Future Work}

The synergies between a GNSS Avionics Based Integrity Augmentation (ABIA) ABIA system and a novel UAS SAA architecture for cooperative and non-cooperative applications were explored. The proposed ABIA system is compatible and interoperable with current Space-Based and Ground-Based Augmentation Systems (SBAS/GBAS), allowing the implementation of an integrated Aircraft-Space-Ground Augmentation (ASGA) network. The integration of ABIA with cooperative and non-cooperative SAA architectures leads to an Integrity Augmented SAA (IAS) solution that is currently evolving to meet the performance requirements for a safe and unrestricted access of UAS to commercial airspace. Simulation case studies were performed on the ABIA/SAA modules in various representative scenarios, also including the presence of directional jammers. According to the simulation results, after the integrity caution flag is generated, the time available for the pilot/autopilot to react (before the integrity warning flag is generated), is sufficient for a variety of mission- and safety-critical tasks. The virtual integration of ABIA into an existing SAA architecture for cooperative and noncooperative scenarios showed that all mid-air collision threats were successfully avoided by implementing suitable trajectory optimisation algorithms. Further research is currently focusing on the following main areas [21-23]:

- Extend the ABAS/ABIA concept to other navigation, communication, surveillance and tracking applications also addressing SAA requirements.

- Investigate ABIA applications and possible evolutions for Next Generation Flight Management System (NG-FMS) for manned and unmanned aircraft.

- Evaluate the potential of ABAS/ABIA to enhance the performance of next generation Communication, Navigation and Surveillance / Air Traffic Management (CNS/ATM) systems for Performance/Intent Based Operations (PBO/IBO) and FourDimensional Trajectory (4DT) management.

- Study possible applications of the ABIA/SAA concepts to advanced mission planning and forensic applications.

\section{References}

1. R. Sabatini, T. Moore and C. Hill, "A New Avionics Based GNSS Integrity Augmentation System: Part 1 - Fundamentals," Journal of Navigation, Vol. 66, No. 3, pp. 363-383, May 2013. DOI: $10.1017 /$ S0373463313000027

2. R. Sabatini, T. Moore and C. Hill, "A New Avionics Based GNSS Integrity Augmentation System: Part 2 - Integrity Flags," Journal of Navigation, Vol. 66, No. 4, pp. 511-522, June 2013. DOI: $10.1017 /$ S0373463313000143

3. R. Sabatini, T. Moore, C. Hill, "A Novel GNSS Integrity Augmentation System for Civil and Military Aircraft," International Journal of Mechanical, Aerospace, Industrial and Mechatronics Engineering, Vol. 7, No. 12, pp. 1433-1449, International Science Index, December 2013.

4. R. Sabatini, T. Moore and C. Hill. "A Novel Avionics-Based GNSS Integrity Augmentation System for UAV Applications," Paper presented at the Royal Institute of Navigation (RIN) Conference on Unmanned Air Vehicles - Sharing the Airspace, Teddington (UK), February 2013.

5. R. Sabatini, T. Moore and C. Hill. "Avionics Based GNSS Integrity Augmentation for Mission- and Safety-Critical Applications," Paper presented at $25^{\text {th }}$ International Technical Meeting of the Satellite Division of the Institute of Navigation: ION GNSS-2012, Nashville (Tennessee), September 2012.

6. E.D. Kaplan and C.J. Hegarty, "Understanding GPS: Principles and Applications," Artech House, Second Edition, 2006.

7. O.M Mubarak and A.G Dempster, "Analysis of Early Late Phase in Single and Dual Frequency GPS Receivers for Multipath Detection,"

Page 10 of 10
The University of New South Wales (Australia), 2010. Available at http://www.gmat.unsw.edu.au/snap/staff/omer_mubarak.htm.

8. P. Ward, "Using a GPS Receiver Monte Carlo Simulator to Predict RF Interference Performance," Proceedings of $10^{\text {th }}$ International Technical Meeting of The Satellite Division of The Institute of Navigation, Kansas City, MO, pp.1473-1482, September 1997.

9. P. Ward, "GPS Receiver RF Interference Monitoring, Mitigation, and Analysis Techniques," NAVIGATION, Journal of the Institute of Navigation, Vol. 41, No. 4 (Winter), pp. 367-391, 1994-95.

10. M.S. Braasch, "On the Characterization of Multipath Errors in Satellitebased Precision Approach and Landing Systems," College of Engineering and Technology, Ohio University, June 1992.

11. R. Sabatini and G. Palmerini, "Differential Global Positioning System (DGPS) for Flight Testing," NATO Research and Technology Organization (RTO) - Systems Concepts and Integration Panel (SCI), AGARDograph Series RTO-AG-160, Vol. 21, Oct 2008.

12. RTCA, "DO-229D - Minimum Operational Performance Standards for Global Positioning System/Wide Area Augmentation System Airborne Equipment," Washington DC, USA, 2006.

13. RTCA, "DO-245A : Minimum Aviation System Performance Standards for Local Area Augmentation System (LAAS), "Washington DC, USA, 2004.

14. P. Rodriguez, R. Sabatini, A. Gardi and S. Ramasamy, "A Novel System for Non-Cooperative UAV Sense-and-Avoid," Paper presented at European Navigation Conference 2013, Vienna, Austria, April 2013.

15. S. Ramasamy, R. Sabatini and A. Gardi, "Towards a Unified Approach to Cooperative and Non-Cooperative RPAS Detect-and-Avoid," Fourth Australasian Unmanned Systems Conference 2014 (ACUS 2014), Melbourne, Australia. DOI: 10.13140/2.1.4841.3764

16. S. Ramasamy and R. Sabatini, "A Unified Approach to Cooperative and Non-cooperative Sense-and-Avoid," 2015 IEEE International Conference on Unmanned Aircraft Systems (ICUAS), Denver, CO, USA, pp. 765 - 773, June 2015. DOI: 10.1109/ICUAS.2015.7152360

17. R. Sabatini, L. Rodríguez, A. Kaharkar, C. Bartel and T. Shaid, "Carrierphase GNSS Attitude Determination and Control System for Unmanned Aerial Vehicle Applications," ARPN Journal of Systems and Software, ISSN: 2222-9833, Vol. 2, Issue 11, pp. 297-322. December 2012.

18. R. Sabatini, C. Bartel, A. Kaharkar, T. Shaid and S. Ramasamy, "Navigation and Guidance System Architectures for Small Unmanned Aircraft Applications," International Journal of Mechanical, Aerospace, Industrial and Mechatronics Engineering, Vol. 8, No. 4, pp. 733-752. International Science Index. 2014. http://waset.org/publications/9998114

19. R. Sabatini, C. Bartel, A. Kaharkar, T. Shaid, L. Rodriguez, D. ZammitMangion and H. Jia, "Low-Cost Navigation and Guidance Systems for Unmanned Aerial Vehicles - Part 1: Vision-Based and Integrated Sensors," Annual of Navigation, Vol. 19, Issue 2, pp. 71-98. December 2012. DOI: $10.2478 / \mathrm{v} 10367-012-0019-3$

20. R. Sabatini, A. Gardi and S. Ramasamy, "A Laser Obstacle Warning and Avoidance System for Unmanned Aircraft Sense-and-Avoid," Applied Mechanics and Materials, Trans Tech Publications, Vol. 629, pp. 355-360, 2014. DOI: 10.4028/www.scientific.net/AMM.629.355

21. S. Ramasamy, M. Sangam, R. Sabatini and A. Gardi, "Flight Management System for Unmanned Reusable Space Vehicle Atmospheric and Re-entry Trajectory Optimisation," Applied Mechanics and Materials," Vol. 629, Trans Tech Publications, Switzerland, pp. 304309. 2014. DOI: 10.4028/www.scientific.net/AMM.629.304

22. S. Ramasamy, R. Sabatini and A. Gardi, "Novel Flight Management Systems for Improved Safety and Sustainability in the CNS+A Context," Proceedings of Integrated Communication, Navigation and Surveillance Conference (ICNS 2015), Herndon, VA, USA, 2015. DOI: 10.1109/ICNSURV.2015.7121225

23. A. Gardi, R. Sabatini, T. Kistan, Y. Lim and S. Ramasamy, "4Dimensional Trajectory Functionalities for Air Traffic Management System," Proceedings of Integrated Communication, Navigation and Surveillance Conference (ICNS 2015), Herndon, VA, USA, 2015. DOI: 10.1109/ICNSURV.2015.7121246 